\title{
Rebuilding patient-physician trust in China, developing a trust-oriented bioethics
}

\section{Citation}

Nie, Jing-Bao, Joseph D. Tucker, Wei Zhu, Yu Cheng, Bonnie Wong, and Arthur Kleinman. 2017. "Rebuilding Patient-Physician Trust in China, Developing a Trust-Oriented Bioethics." Developing World Bioethics (September 18). doi:10.1111/dewb.12172.

\section{Published Version}

doi:10.1111/dewb.12172

\section{Permanent link}

http://nrs.harvard.edu/urn-3:HUL.InstRepos:34334599

\section{Terms of Use}

This article was downloaded from Harvard University's DASH repository, and is made available under the terms and conditions applicable to Open Access Policy Articles, as set forth at http:// nrs.harvard.edu/urn-3:HUL.InstRepos:dash.current.terms-of-use\#OAP

\section{Share Your Story}

The Harvard community has made this article openly available.

Please share how this access benefits you. Submit a story.

Accessibility 


\section{Editorial}

\section{Rebuilding Patient-physician Trust in China, Developing a Trust-Oriented Bioethics}

Jing-Bao Nie, Joseph D. Tucker, Wei Zhu, Yu Cheng, Bonnie Wong and Arthur Kleinman

\section{Correspondence:}

Jing-Bao Nie, Bioethics Centre, University of Otago, 71 Frederick St., Dunedin, New Zealand; email: jing-bao.nie@otago.ac.nz.

In a short period of nearly four decades, China, with one fifth of the world's population, has rapidly evolved from a predominantly agricultural, poor and developing country to an upper middle-income country. At the same time, China faces numerous daunting social challenges. One of them is the widespread, profound, and advancing crisis of patient-physician trust. Among the many manifestations of this crisis is an unprecedented process characterized by rapidly increasing levels of violence involved in disputes between patients and their relatives against medical professionals and institutions.

Like other challenges that China faces, this crisis of trust in the health sector is by no means merely a Chinese problem. There is much convincing evidence that it is a global issue, emerging in developing and developed societies alike, although the scale and depth of such a crisis may vary considerably from one place to another. More generally, a serious crisis of trust can be observed across geographic areas and societal sectors. It affects all professions, businesses, the media, governments, and international affairs.

Though its significance often goes unrecognized, trust plays a vital role for interpersonal and social life as well as healthcare. In the field of bioethics, however, attention paid thus far to the question of trust in general, and to patient-physician trust in China in particular, is far from 
sufficient in spite of some pioneering studies. ${ }^{1}$ Such deficits in bioethical scholarship is in marked contrast to the fields of social and political sciences, where trust has been a key subject for the past few decades, with a large and growing literature. Due to its essential role for good social life and good healthcare, trust deserves a place in the central agenda of bioethics in China and globally.

According to Confucianism - one major cultural framework of morality in the Chinese tradition - an essential device for thinking about and discussing ethical and political matters is "rectifying names". Names are not merely words, but are always morally laden and practically pertinent. For this thematic issue in particular, we must first clarify the usage of a key term. The phrase "yihuan guanxi", "physician-patient relationship" or "doctor-patient relationship", has been conventionally employed in academic literature, the mass media, and everyday discourse in both Chinese and English. In this issue, however, we choose to use the term "huanyi guanxi", "patient-physician relationship" or "patient-doctor relationship", to underscore that health care should be patient-centred and that the ultimate moral end of medicine is to serve patients and improve their health and welfare. In this relationship, patients' relatives and other medical professionals like nurses and health officials are included on the patient and physician sides, respectively.

The topic - patient-physician trust and mistrust — is rife with conflicting personal experiences, competing institutional norms, various socio-political forces, and different local life worlds in scope. This complex set of elements calls for research that employs methods and

1 E.g. Pellegrino ED, Veatch RM, Langan JP. editors. Ethics, Trust, and the Professions: Philosophical and Cultural Aspects. Washington DC: Georgetown University Press, 1991; O’Neill O. Autonomy and Trust in Bioethics, Cambridge: Cambridge UP, 2002; Henaghan M. Health Professionals and Trust: The Cure for Healthcare Law and Policy. London: Routledge; 2011; Hui EC. The Contemporary Healthcare Crisis in China and the Role of Medical Professionalism. Journal of Medicine and Philosophy 2002; 35:477-492; Tao J. editor. China: Bioethics, Trust, and the Challenge of the Market. Berlin: Springer; 2008; Zhang X, Sleeboom-Faulkner M. Tension between Medical Professionals and Patients in Mainland China. Cambridge Quarterly of Healthcare Ethics 2011; 20: 458-465. 
conceptual frameworks drawn from a range of academic disciplines including the social sciences and bioethics.

This thematic issue presents papers by an international team of anthropologists, sociologists, sinologists, physicians, philosophers and bioethicists from China (including Hong Kong), the United States and New Zealand. Methodologically, the various contributions integrate systematic and in-depth empirical investigation with normative bioethical inquiries. Based on highly original and collaborative interdisciplinary research, they altogether aim to achieve the following twin overall aims, one focusing upon China and the other upon bioethics:

- To document the phenomenon of patient-physician mistrust in China, identifying the major social and institutional sources of mistrust, examining the central ethical issues involved, and searching for mechanisms of reforming social and healthcare institutions and practices to rebuild patient-physician trust;

- To elaborate the implications of patient-physician trust and mistrust in China for bioethics globally and, more generally, to develop a theoretical framework of a trustoriented bioethics.

Patient-physician mistrust in China and trust-oriented bioethics have numerous complicated and interacting dimensions to investigate. Individually and collectively, six papers in this issue explore methodically the following four concerns:

- To present first-hand qualitative empirical data. Although there have been many surveys focused on patient-physician relationships in China, there have been few qualitative investigations exploring the social and cultural basis of trust and mistrust. Through semistructured interviews and focus groups, our studies have collected the individual opinions and experiences of more than 300 patients, healthcare providers, and healthcare officials and administrators. With particular attention paid to the dynamics and complexity of "local moral worlds", our studies document the struggles of patients and their relatives, medical professionals and healthcare officials in China's ever-changing healthcare system, the institutional and socio-political environment. 
- To identify the main sources of patient-physician mistrust. Through anthropological inquires and sociological analysis, our studies examine why patient-physician mistrust has deepened and how trust can be restored. Patient-physician trust and mistrust are explored at four different levels: 1) interpersonal, 2) professional, 3) institutional, and 4) political and societal. Our studies highlight structural factors, in particular within health and social institutions, that contribute to patient-physician trust, or rather, its deterioration.

- To examine the major normative or ethical dimensions involved and present the key elements for developing a trust-oriented bioethics. There are numerous challenging moral issues surrounding patient-physician relationships, particularly in the Chinese context. While we do engage with such perspectives as patients' rights and medical professionalism or professional ethics, our studies do not follow any of the existing major bioethical theories and approaches throughout. Most importantly, we argue for the necessity of a trust-oriented theoretical framework for bioethics and present some elements of such a framework. Additionally, we propose that a number of theoretical and practical bioethical issues need to be recast through the lens of patient-physician trust.

- To offer health and social policy recommendations. Bioethics is primarily a branch of practical (not merely applied) ethics. The current health and social policy scaffolding of legal procedures, administrative regulations, and normative practices in China is insufficient to cope with the rising level of patient-physician disputes. This policy disorientation and failure have fueled mistrust between patients and health professionals and institutions. To rebuild patient-physician trust in China, and thus improve healthcare in general, our team has produced a White Paper which includes a set of suggestions designed especially for health systems and clinical settings ${ }^{2}$. The articles in this issue explore the sociological and ethical rationales of these recommendations and canvass other possible policy mechanisms.

2 Tucker JD, Wong B, Nie JB, Kleinman A and the Patient-physician Trust Team. Rebuilding patientphysician trust in China. The Lancet 2016; 338: 755. 
The first two papers are anthropological and sociological studies of the broader sociopolitical, cultural and healthcare context of patient-physician mistrust and its major sources in contemporary China. Yunxiang Yan demonstrates how patient-physician mistrust, and patientphysician relations in general, has been a part of a grand moral and political transformation unfolding in China over the past few decades; this include the growth of individualization and the rising awareness of the values of human dignity, respect, and individual rights. Based on two years of ethnographic research, Cheris Chan examines the major sources of medical mistrust at societal, institutional, and interactional levels. She highlights the role of funding mechanisms behind China's healthcare system, whereby public hospitals and health professionals alike are largely forced to finance themselves, in generating mistrust.

A qualitative study was carried out in 2013 and 2014, involving in-depth semi-structured interviews and focus groups with nearly 200 patients and their relatives, health professionals, and hospital administrators in Guangdong, a southern coastal province. The next paper reports the main empirical findings of this study and key ethical issues regarding health professionals. JingBao Nie et al. show how medical professionals are trapped in a vicious circle of mistrust which involves such factors as physicians constrained by fear and a perceived need for self-protection, communication difficulties, discontent patients, medical disputes and violence against health professionals, and negative media coverage. In order to break this vicious circle, the authors propose promoting medical professionalism by rectifying the institutional conflict of interest, and upholding the contemporary principle of the primacy of patient welfare in addition to the traditional Chinese ideal of "medicine as the art of humanity".

In contrast to western societies, there are two common and socio-culturally distinctive Chinese practices in healthcare: "hongbao" ("red envelopes" or monetary gifts) from patients to physicians, and "guanxi jiuyi" (seeking better healthcare through personal connections). Drawing on first-hand empirical information derived from anthropological and sociological research conducted with patients and health professionals in different locations, two papers explore the socio-cultural and ethical dimensions of these practices. For Wei Zhu et al., the notorious issue of "red envelopes" seriously undermines the sense of integrity and pride associated with the medical profession. In order to reclaim "medicine as the art of humanity" in contemporary 
China, it is thus necessary to cultivate and strengthen a moral environment that would root out corruption and allow professional pride to flourish. Xiang Zou et al. argue that the popularity of seeking healthcare through guanxi or personal connections is itself a sign of patient-physician mistrust and damages institutional trust in the long run, though it may appear to help establish confidence in individual cases. They therefore propose that patient-physician trust be developed in ways that are based on professionalism and professional ethics, rather than on guanxi.

The final paper in this thematic issue sets out explicitly the implications of patientphysician trust and mistrust in the Chinese context for bioethics globally. Jing-Bao Nie et al. argue that the crisis of patient-physician trust in China demands a trust-oriented approach and offer some basic features of such a theoretical framework. Quality healthcare delivery within a robust healthcare system will never be achieved without effectively addressing the issues of trust and mistrust. Trust should be as vital as such central concepts as autonomy and justice for bioethics as both an academic field and a public domain on a global scale.

To conclude, it should be emphasized that the situation in China and the crisis of trust now unfolding on a global scale should not be framed in totally negative terms. As the two Chinese characters for crisis, weiji, aptly reflect, any crisis presents both dangers and opportunities simultaneously. In the Chinese context, distrust and mistrust of medical professionals and healthcare systems amongst individual patients and patient populations means that people are developing higher expectations of competence, caring, respect, dignity, recognition, rights, high-quality services, and active participation. In spite of its immediate and long-term negative consequences, the widespread and profound mistrust therefore presents opportunities to reform existing but ethically unsound medical practices and institutions, and ensure the moral accountability of institutions and individuals in power.

Although these studies primarily concern China, we believe that the interdisciplinary research assembled here holds implications far beyond China itself. Taken together, the articles in this thematic issue, and others published elsewhere by our team, ${ }^{3}$ constitute a meaningful

3 Ibid; Tucker JD, Cheng Y, Wong B, Gong N, Nie JB, Zhu W, ... Kleinman A, the Patient-physician Trust Project Team. 2015. Patient-physician mistrust and violence against physicians in Guangdong 
Chinese contribution to global bioethics by alerting the international bioethics community to the problems of patient-physician mistrust, the essential role of patient-physician trust in healthcare, and an urgent need to develop a trust-oriented bioethics. In turn, global bioethics may help China and other countries facing similar challenges to rebuild, sustain, and advance patient-physician trust so that more adequate health-care can be provided for every person in need of care. And a trust-oriented bioethics may join with other trust-promoting academic efforts and social forces so that we may all have a more peaceful and trustworthy world in which to live.

\section{Acknowledgements:}

This project is financially supported by a Harvard China Fund grant, the Harvard University Asia Center, and a grant from the China Medical Board. The papers published here, except one, were presented and discussed at an international symposium entitled "Rebuilding Patient-physician Trust in China" held at the Harvard Shanghai Center on 10-11 October 2015. We wish to thank other participants including Yali Cong, Zhizheng Du, Shanlian Hu, Amanda Kerrigan, Mengfeng Li, Benjamin Liebman, Yonghui Ma, Daniel Tsai, Dujian Tsai, Lijie Wang, William Wong, Zeping Xiao, Juncai Xu, Yang Yang, Daqing Zhang, Mingjie Zhao, and Jianfeng Zhu for their valuable contributions. We are grateful to Lun Li who organized an international symposium at Hunan Normal University in Changsha on 13-14 January 2014. We also thank Paul Sorrell for his professional editing of most papers in this thematic issue.

\section{Biographies}

Jing-Bao Nie, BMed, MMed, PhD, is Professor at the Bioethics Centre, University of Otago, New Zealand; Adjunct Professor at Peking University Medical School, China; and Associate of Harvard University Asia Centre, USA. His publications include Medical Ethics in

Province, China: a qualitative study. BMJ Open 2015;5:e008221.doi:10.1136/bmjopen-2015-008221;

Tucker JD, Nie JB, Cheng Y, Zhu W, Kleinman A. Reviving medicine as the art of humanity in China. The Lancet 2014; 383: 1462-1563. 
China (Routledge, 2011) and a co-edited thematic issue on the methodologies of transcultural and global bioethics in Kennedy Institute of Ethics Journal (2016).

Joseph D. Tucker, MD, PhD, AM is an Assistant Professor of Medicine at UNC Chapel Hill and Director of UNC Project-China. He co-leads a five-year research study on the social science and ethical implications of HIV cure research. He has a special interest in nurturing and instilling patient-physician trust in the Chinese context.

Wei Zhu, $\mathrm{PhD}$, is Associate Professor at the Center for Applied Ethics and Department of Social Sciences, Fudan University, China. Her research areas include informed consent, physicianpatient relationship, social justice, human rights, genetic ethics and research oversight in low and middle income countries.

Yu Cheng received his Ph.D. from Sun Yat-sen University (SYSU) and his M.A. from South Central University for Nationalities. He was a post-doctoral fellow at Yale University, He is Professor in the Department of Anthropology at SYSY and the Director of the Center for the Medical Humanities at the Zhongshan School of Medicine at SYSU. His current research interests focus on migrant health, elderly care and the patient-physician relationship in China.

Bonnie Wong is a PhD student in the joint UC Berkeley/ UCSF program in Medical Anthropology, and an MD candidate at Stanford School of Medicine. She received her MSc in Medical Anthropology at Oxford as a Knox Scholar and her BA at Harvard in Biology.

Arthur Kleinman, MD, MA, is professor of medical anthropology in the Department of Global Health and Social Medicine and professor of psychiatry at Harvard Medical School. He is the Esther and Sidney Rabb professor of anthropology in the Department of Anthropology in the Faculty of Arts and Sciences (FAS), and was the Victor and William Fung Director of Asia Center at Harvard University from 2008-2016. 